\title{
REJUVENASI PARADIGMA DAKWAH DI ERA 4.0
}

\author{
Mohammad Darwis \\ Institut Agama Islam Syarifuddin Lumajang \\ mohammad.darwis70@gmail.com
}

\begin{abstract}
This article discusses rejuvenation of Islamic da'wah paradigm in the fourth industrial revolution era, by critically examining the process of social change in society. The era developes technology, while bringing positive and negative effects to society. The public will inevitably face the impact of Industry 4.0 , in the form of political, cultural, economic, and ideological aggression. This will further marginalize and disqualify the traditional structures of established communities. Likewise the development of technology as intended also becomes a challenge to the da'wah movement, both concrete and ideological. The emergence of science and technology in this era could have a destructive effect on the da'wah movement and the process of broadcasting Islamic missions to the public. Likewise the emergence of various understandings and ideologies can shift the existence of da'wah, which in turn will push the scope and pace of the da'wah movement. Therefore, in this area, the da'wah movement is required to be able to provide new paradigms that are able to transfer messages of Islamic teachings to the public, so that the existence of Islamic da'wah can always be maintained. Based on the description above, this article describes the challenges and opportunities of da'wah in era 4.0, how to find a new paradigms, the significance of Islamic da'wah in response to technological developments, and the reconstruction of da'wah in era 4.0. Then, at the end of this articles, there is a recommendation about how to do effective da'wah in the fourth industrial revolution era.
\end{abstract}

Key Words: Paradigm of Da'wah, Da'wah, The Fourth Industrial Revolution Era, Rejuvenation 


\section{PENDAHULUAN}

Islam dan peradaban sudah berdealektika sangat panjang. Bahkan sebelum dunia barat berada pada puncak kejayaan, Islam telah mencapai kejayaannya terlebih dahulu. Pada abad ke-7 Islam begitu Berjaya dan mewarnai berbagai dinamika global. Islam sangat maju dan terkenal diberbagai pejuru dunia bahkan ilmu pengetahuannya selama ini digali untuk perdamaian umat manusia. Dealektika Islam dan peradaban Islam telah terangkum dan terekam dalam dimensi dakwah. ${ }^{1}$ Dakwah dalam berbagai bentuk telah mengantarkan Islam sebagai agama universal yang dengan mudah dan cepat diterima di seluruh penjuru dunia, tidak hanya di Timur Tengah, melainkan di negara-negara Asia, Afrika, Eropa, bahkan Australia dan Amerika. Itu semua adalah karena rutinitas proses dakwah yang dilakukan oleh individu-individu muslim sebagai juru dakwah. ${ }^{2}$

Melihat hal tersebut, dapat diketahui bahwa dakwah sangatlah penting dalam Islam. bahkan dakwah dan Islam seperti menjadi satu kesatuan yang tidak dapat dipisahkan. Oleh karena itu, dakwah merupakan kewajiban bagi setiap muslim (fardhu 'ain), akan tetapi dalam konteks tertentu dakwah juga bisa menjadi sebuah kewajiban yang kolektif (fardhu kifayah). ${ }^{3}$ Dasar hukum kewajiban dakwah tersebut terdapat dalam surat Ali Imran ayat 104 yaitu "dan hendaklah ada diantara kamu segolongan umat yang menyeru kepada kebajikan, menyuruh kepada yang ma'ruf dan mencegah dari yang mungkar, merekalah orang-orang yang beruntung".

Setiap individu dengan berbagai profesi yang berbeda-beda memiliki kewajiban berdakwah karena berdakwah dapat dilakukan diberbagai multidimensi kehidupan. Jadi berdakwah tidak hanya dilakukan dengan menggunakan lisan maupun tulisan, namun berdakwa juga bisa dilakukan dengan cara memiliki perilaku yang baik ataupun dengan aksi sosial. Seorang ulama yang professional, selain memahami konteks yang akan dibicarakan, juga harus memahami keadaan dan

\footnotetext{
${ }^{1}$ Razikin Juraid, http://m.hidayatullah.com (diakses tanggal 08 Februari 2019)

2 Samsul Munir Amin, Rekonstruksi Pemikiran Dakwah Islam (Jakarta: Amzah, 2008), hal. ix

${ }^{3}$ Ibid, hal. 9
} 
kebiasaan dari masyarakat yang akan menjadi sasaran dakwahnya. Hal ini dilakukan agar dakwah yang disampaikan akan dengan mudah meresap di hati masyarakat. ${ }^{4}$

Dakwah harus dilakukan dengan berbagai cara agar selalu dapat diterima oleh masyarakat, hal ini yang kemudian menjadikan dakwah sebagai sebuah proses perubahan sosial, yang mana perubahan nilai pada tingkat individu-individu dapat merambat ke masyarakat akibat interaksi sosial antar individu, baik sebagai da'i maupun mad'u. dengan timbulnya pandangan bahwa dakwah dipandang sebagai proses komunikasi dan proses perubahan sosial, maka strategi dakwah yang terfokus dengan cara lisan menjadi tidak memadai lagi. Apalagi jika aktivitas dakwah berhadapan dengan berbagai masalah dan tantangan sosial di era media baru saat ini. 5

Di Indonesia, jumlah penduduk perkampungan akan makin berkurang diganti oleh mayoritas masyarakat perkotaan; baik karena urbanisasi maupun karena perkampungan yang berubah menjadi urbanized. Di masa itu, masyarakat akan banyak yang bekerja dibidang industri jasa dan perdagangan, masyarakat yang relatif terdidik akan semakin tinggi jumlahnya, rata-rata masyarakat berpendidikan SD akan diganti dengan rata-rata lulusan SLTA karena program wajib belajar 12 tahun. Berbagai bentuk industri dan bisnis akan makin berubah dikarenakan kita telah memasuki Era Perdagangan Bebas ASEAN yang dimulai pada tahun 2003 yang lalu dan Era Perdagangan Bebas Dunia di tahun 2020 ke atas yang akan datang. ${ }^{6}$

Memasuki era industri 4.0,7 tantangan terhadap gerakan dakwah sangat kompleks, baik yang bersifat konkret maupun ideologis. Munculnya ilmu pengetahuan dan teknologi dalam era ini bisa mengakibatkan dampak destruktif bagi gerakan dakwah dan proses penyiaran misi Islam kepada masyarakat. Demikian

\footnotetext{
${ }^{4}$ Yedi Purwanto, dkk, Peran Teknologi Informasi dalam Perkembangan Dakwah Mahasiswa Jurnal Sosioteknologi Vol. 16, No. 1, April 2017, hal. 95

${ }^{5}$ Efa Rubawati, Media Baru: Tantangan dan Peluang Dakwah Jurnal Studi Komunikasi, Vol. 2, Ed. 1, Maret 2018, hal. 127-128

${ }^{6}$ Alex Sobur, Dakwah Alternatif di Era Global: Suatu Pendekatan Perubahan Sosial Mimbar, No. 4, Th. XVII, Oktober-Desember 2001, hal. 414

${ }^{7}$ Era industri 4.0 merupakan konsep penggabungan teknologi digital dan internet dengan industri konvensional yang pada akhirnya bertujuan meningkatkan produktivitas, efisiensi dan layanan konsumen secara signifikan. Secara sederhana, era industri 4.0 adalah abad internet dan teknologi. Pada abad ini, pemuda Islam harus menyiapkan kompetensi komunikasi multimodal. Selanjutnya baca Razikin Juraid, http://m.hidayatullah.com (diakses tanggal 08 Februari 2019)
} 
pula munculnya berbagai pemahaman dan ideologis dapat menggeser eksistensi dakwah, yang pada gilirannya akan mendesak lingkup dan laju gerakan dakwah. Oleh karena itu, perlu adanya rejuvenasi paradigma dakwah, agar eksistensi dakwah tidak tergeser di era industri 4.0 ini.

\section{PEMBAHASAN}

\section{Mengenal Era 4.0: Peluang dan Tantangannya bagi Dunia Dakwah}

Perkembangan media massa berawal pada kemajuan teknologi komunikasi dan informasi dekade 1970-an dan masuknya zaman industrialisasi negara-negara barat yang akhirnya sedikit banyak membantu terbitnya surat kabar, radio, dan televisi. Belum lagi adanya banjir teknologi yang juga membuka banjir informasi era satelit seperti adanya perkembangan teknologi internet, sehingga jarak ruang dan waktu menjadi demikian tidak masalah. Penggunaan internet ini juga berpengaruh terhadap perkembangan televisi, radio, dan surat kabar. ${ }^{8}$

Dan hadirnya internet sebagai ruang sosial baru dengan masyarakat yang menggunakan internet akan menjadi sebuah peluang dan tantangan baru dalam aktivitas dakwah Islam. Hal ini dikarenakan agar dakwah Islam di era Informasi ini tetap relevan, responsif, efektif dan produktif. ${ }^{9}$ Pada era media baru saat ini, agama dan spiritualitas umumnya tampil kembali sebagai kebutuhan yang dianggap mendasar. Bukan karena mereka begitu menarik, melainkan lebih disebabkan oleh berbagai hal luaran, seperti ambruknya ideologi-ideologi raksasa, materialisme kultural yang akhirnya dirasakan dangkal, perkembangan mutakhir spekulasi ilmiah tentang intelegensia kosmik, dan kekosongan batin manusia sekuler yang semakin akut.

Dan akhirnya agama dan spiritualitas menjadi gaya hidup baru bagi masyarakat muslim saat ini. Agama dan spiritualitas tidak hanya dapat ditemui di tempat-tempat sakral, seperti rumah ibadah, tetapi juga dapat ditemui di hampir setiap tempat. Untuk kesekian kalinya, agama dan bentuk-bentuk spiritualitas kembali berkesempatan untuk mengambil peran utama dalam kehidupan sosial

\footnotetext{
${ }^{8}$ Samsul Munir Amin, Rekonstruksi . . . hal. 186-187

${ }^{9}$ Efa Rubawati, Media Baru . . . hal. 136
} 
manusia. ${ }^{10}$ Masyarakat sekarang ini akan mencari informasi tentang keagamaan untuk menjawab permasalahan sehari-hari melalui media internet. Maka tidak heran, jika masyarakat sekarang ini lebih mengandalkan "google" dari pada langsung bertanya ke ustadz maupun orang tua yang notabene sudah lebih faham dan mengerti.

Perubahan sosial inilah yang dijadikan oleh para aktivis dakwah sebagai sebuah peluang dakwah Islam di era media baru saat ini. Jumlah digital native yang terus bertambah akan menjadi sasaran dan penerima dakwah di masa depan. Meskipun demikian perlu diingat juga bahwa mad'u dalam konteks masyarakat jejaring sosial adalah orang yang bersifat aktif. Hal ini karena mereka tidak hanya dapat menerima pesan, namun juga dapat mengkritiki, merespon, mengomentari bahkan melakukan reproduksi pesan-pesan dakwah. ${ }^{11}$

\section{Redefinisi Dakwah: Upaya Menemukan Paradigma Baru}

Dakwah dalam istilah etimologi berasal dari bahasa Arab da'a - yad'u da'watan yang berarti mengajak, menyeru, dan memanggil. Kata dakwah telah berkali-kali disebut didalam Al-Qur'an yaitu sebanyak 213 kali. ${ }^{12} \mathrm{Hal}$ ini menjadi bukti bahwa dakwah sangatlah penting dalam perkembangan agama Islam, sehingga Allah berkali-kali menyebut kata dakwah dalam Al-Qur'an.

Sedangkan secara terminologi, menurut Syaikh Ali Mahfudz, dakwah adalah memotivasi manusia untuk berbuat kebajikan, mengikuti petunjuk, memerintahkan kebaikan dan mencegah kemungkaran, agar mereka memperoleh kebahagiaan di dunia dan di akhirat. ${ }^{13}$ Menurut Dr. Abdul Wadud Nafis, dakwah diartikan sebuah kegiatan untuk menyeru dan mengajak manusia untuk memahami dan mengamalkan ajaran Islam sesuai dengan Al-Qur'an dan sunnah Nabi Muhammad SAW. ${ }^{14}$

\footnotetext{
10 Ibid, hal. 130

$11 \mathrm{lbid}$, hal.138

${ }^{12}$ M. Fuad Abdul Baqi, Al-Mu'jam Al-Mufahraz li Alfazh Al-Qur'an (Cairo: Dar Al-Kutub Al-

'Arabiyyah), hal. 120

${ }^{13}$ Syaikh Ali Mahfudz, Hidayat Al-Mursyidin ( ), hal. 17

${ }^{14}$ Abdul Wadud Nafis, Metode Dakwah Teori dan Praktik (Jakarta: Mitra Abadi, 2009), hal. 7
} 
Menurut M. Natsir, dakwah adalah usaha-usaha menyerukan dan menyampaikan kepada seluruh manusia, konsepsi Islam tentang pandangan dan tujuan hidup manusia di dunia ini, dan yang meliputi amar ma'ruf nahi mungkar dengan berbagai macam cara dan media yang diperbolehkan akhlak dan membimbing pengalamannya dalam perikehidupan bermasyarakat dan perikehidupan bernegara. ${ }^{15}$ Pengertian-pengertian tersebut, meskipun berbeda pengertian namun memiliki maksud yang sama. Adapun menurut hemat penulis, yang dimaksud dengan dakwah adalah proses penyampaian ajaran Islam kepada umat manusia dengan cara mengajak masyarakat untuk berbuat amar ma'ruf nahi mungkar.

Namun selama ini masyarakat telah miss understanding dalam memaknai dan memahami dakwah, yang mana dakwah hanya dipandang sebagai sebuah ceramah atau tabligh. Pemahaman seperti itu jelas keliru karena mempersempit makna dari dakwah itu sendiri. Karena ceramah dan tabligh hanyalah sebagian kecil dari metode dakwah. Sebenarnya pengertian dakwah amatlah luas, oleh karena itu untuk memahami dakwah diperlukan dua pendekatan sebagai berikut: Pertama, memahami dakwah sebagai ilmu pengetahuan sebagaimana ilmu-ilmu yang lain. Ilmu dakwah ini timbul karena adanya fenomena alam yang bersifat free will (akibat pikiran bebas) dan secara spesifik ilmu ini sebagai aplicatif science. Kedua, memahami dakwah secara praktis sebagai suatu tindakan dan aksi untuk dikembangkan. ${ }^{16}$

\section{Signifikansi Dakwah Islam dalam Merespon Perkembangan Teknologi}

Sepanjang sejarah Islam, dakwah yang disebarkan di masyarakat selalu memperhatikan perkembangan peradaban yang ada, mulai dari zaman nabi-nabi ${ }^{17}$

\footnotetext{
${ }^{15}$ M. Natsir, Fungsi Dakwah Perjuangan dalam Abdul Munir Mulkhan, Ideologi Gerakan Dakwah (Yogyakarta: Sipres, 1996), hal. 52

${ }^{16}$ Samsul Munir Amin, Rekonstruksi ... hal. 11

${ }^{17}$ Para nabi selalu diberikan mukjizat sesuai dengan peradaban yang terjadi di zamannya. Seperti nabi Musa as yang diutus pada zaman dimana umatnya sedang mendalami ilmu sihir, sehingga nabi Musa as diberikan mukjizat dengan tongkatnya yang bisa berubah menjadi ular. Nabi Isa as yang diutus pada zaman dimana umatnya sedang mendalami ilmu kedokteran, sehingga nabi Isa as diberikan mukjizat bisa menyembuhkan penyakit kusta, penyakit belang, menyembuhkan orang buta (buta sejak lahir), bahkan bisa menghidupkan orang yang sudah mati. Dan juga nabi Muhammad saw yang diutus pada zaman
} 
sampai kepada zaman para ulama'. Lihat saja dakwah yang dilakukan oleh Wali Songo ${ }^{18}$ di Indonesia, dakwah yang dilakukan Wali Songo ini merupakan contoh yang paling tepat dalam menyiarkan agama Islam. Mereka dikenal dengan dakwah yang kultural, membaur, dan memanfaatkan budaya setempat untuk menyiarkan ajaran Islam. ${ }^{19}$

Dalam kenyataannya antara dakwah dengan realitas sosio-kultural selalu saling mempengaruhi. Karena dakwah Islam mampu memberikan pengaruh terhadap lingkungannya, dalam artian dapat memberikan dasar filosofis, arah, motivasi, dan pedoman-pedoman perubahan masyarakat, sehingga mewujudkan masyarakat baru dengan budaya yang berbau Islam. Di sisi lain, dakwah Islam juga dipengaruhi oleh perubahan masyarakat dalam arti eksistensinya, corak, dan gayanya serta arah yang dituju. ${ }^{20}$

Terjadinya revolusi industri ke-4 menjadikan teknologi berkembang sangat luar biasa, sekaligus membawa efek positif dan negatif bagi masyarakat. Masyarakat mau tidak mau akan berhadapan dengan dampak dari era 4.0 ini dalam bentuk agresi politik, kultural, ekonomi, dan ideologi yang memarjinalisasikan dan mendiskualifikasikan struktur tradisional masyrakat yang telah mapan. Pada dataran ini gerakan dakwah dituntut mampu memberikan paradigma-paradigma baru yang mampu mentransfer pesan-pesan ajaran Islam kepada masyarakat. Signifikansi dakwah Islam dalam perkembangan tata nilai masyarakat, adalah bagaimana cara pandang masyarakat yang berubah tersebut, diarahkan kepada nilai-nilai positif yang berasal dari cara pandang dan ajaran Islam. Dengan demikian, perubahan tersebut tetap berada pada koridor ajaran-ajaran Islam. Oleh karena itu, dakwak

dimana umatnya sedang mendalami ilmu syair, sehingga nabi Muhammad saw diberikan mukjizat berupa Al-Qur'an.

${ }^{18}$ Wali Songo merupakan para penyebar dakwah Islam yang ada di Jawa. Wali Songo ini berjumlah sembilan orang. Jadi begitu salah satu anggota Wali Songo ini meninggal, maka akan digantikan dengan wali yang lain. Wali Songo yang terkenal adalah Sunan Maulana Malik Ibrahim, Sunan Ampel, Sunan Giri, Sunan Drajat, Sunan Bonang, Sunan Kudus, Sunan Muria, Sunan Kalijaga, Sunan Gunungjati.

${ }^{19}$ Baca Yuliyatun Tajuddin, Wali Songo dalam Strategi Komunikasi Dakwah Jurnal Addin, Vol. 8, No.2, Agustus 2014, hal. 369

${ }^{20}$ Samsul Munir Amin, Rekonstruksi . . . hal. 65, 167-168 
Islam harus tetap ada dalam perkembangan dan perubahan tata nilai di masyarakat. ${ }^{21}$

\section{Rekonstruksi Dakwah di Era 4.0}

Memahami esensi dakwah, kegiatan dakwah ini sering dipahami sebagai upaya untuk memberikan solusi Islam terhadap berbagai masalah di kehidupan, baik yang bertalian dengan masalah 'ubudiyah, mu'amalah, maupun ijtimaiyah. ${ }^{22}$ Adapun konstruk dakwah sangat dipengaruhi oleh kualitas interaksi antara pembakuan ideologi dasar dengan kreatifitas para pendukung dakwah dalam menampilkan ideologi tersebut sesuai dengan struktur dan pola kultur yang berkembang. ${ }^{23}$ Selain itu, dakwah Islam seharusnya tidak semata-mata berorientasi pada kesemarakan tapi banyak diarahkan kepada pendalaman dan pengembangan wawasan. Hal ini sangat penting karena mengingat dalam kehidupan masyarakat yang majemuk, diperlukan sikap yang terbuka tetapi tidak larut, diperlukan sikap kosmopolitan tetapi berkepribadian. ${ }^{24}$ Apalagi dengan semakin berkembangnya ilmu pengetahuan dan teknologi komunikasi, maka dakwah Islam pun harus bisa memanfaatkan kemajuan teknologi tersebut.

Peradaban umat manusia pada abad ke-21 ini merupakan era teknologi informasi yang sangat canggih. John Naisbitt mengungkapkan "we are moving toward the capabality to communicate anything to anyone, anywhere, anyform-voice, data, textor emage at the speed of light" yang mana ini berarti bahwa kita sekarang ini sedang berada pada perkembangan komunikasi yang membahas tentang apapun, kepada siapapun, dimanapun, dan juga berbentuk apapun baik itu suara, data, tulisan maupun gambar yang bergerak dengan menggunakan kecepatan suara. ${ }^{25}$ Ungkapan tersebut merupaka sedikit gambaran dari adanya perkembangan dan kecanggihan teknologi yang sedang menghadang kita saat ini. Tak terkecuali Indonesia, yang dewasa ini tengah dipacu dengan proses industrialisasi. Perubahan

\footnotetext{
${ }^{21}$ Ibid, hal. 64

${ }^{22}$ Ibid, hal. 167

${ }^{23}$ Mohammad Abdul Aziz, Netizen Jurnalisme dan Tantangan Dakwah di Media Baru Islamic Comunication Journal, Vol. 3, No. 2, Juli-Desember 2018, hal. 134

${ }^{24}$ Samsul Munir Amin, Rekonstruksi . . . hal. 168

${ }^{25}$ Chairil Anwar, Islam dan Tantangan Kemanusiaan Abad XXI (Yogyakarta: Pustaka Pelajar, 2000), hal. $65-66$
} 
sosial yang terjadi di masyarakat antara lain ditandai dengan munculnya lembagalembaga baru. Lembaga-lembaga baru ini awalnya hanya sebagai prasyarat yang mendukung proses industrialisasi, tapi selanjutnya -setelah industrialisasi ini terjadilembaga-lembaga baru tersebut adalah dampaknya. ${ }^{26}$ Oleh karena itu, era industri 4.0 harus selalu mendapat sorotan dari umat Islam sendiri. Hal ini dikarenakan agar dakwah Islam bisa terus berlanjut di era teknologi ini. Dan di era ini pula kita mengetahui dengan jelas keberadaan umat Islam yang sebenarnya di seluruh penjuru dunia.

Islam pun tidak pernah melarang umatnya untuk menggukan komputer, internet, dan teknologi informasi lainnya selama hal itu masih mengarah kepada halhal yang positif dan memberikan nilai tambah dalam upaya pengabdian seorang hamba kepada Sang Pencipta. Karena itu, strategi dakwah harus dikembangkan dan juga memanfaatkan kecanggihan teknologi informasi. Dan saat ini, kita sudah tiba di suatu masa dimana para da'i mendapat tantangan yang sangat kompleks untuk mencarikan solusi dalam memberikan problem solving. Para da'i di tuntut untuk dapat menerjemahkan pesan Islam sesuai dengan manajemen dakwah yang modern, efektif, dan efisien kepada masyarakat luas, sehingga Islam akan semakin luas dan mudah dimengerti serta tidak disalah artikan oleh non-muslim. ${ }^{27}$

\section{KESIMPULAN}

Era revolusi industri 4.0 merupakan konsep penggabungan teknologi digital dan internet dengan industri konvensional yang pada akhirnya bertujuan meningkatkan produktifitas, efisiensi dan layanan konsumen secara signifikan. Sehingga menyediakan peluang sekaligus tantangan bagi para aktivis dakwah. Hal ini dikarenkan perubahan sosial yang terjadi di masyarakat, yang mana masyarakat sekarang ini lebih banyak mencari pengetahuan tentang keagamaan melalui internet daripada berguru langsung kepada yang ahli. Oleh karenanya strategi dakwah harus dikembangkan dan juga memanfaatkan kecanggihan teknologi informasi. Hal ini berarti juga mengharuskan para aktivis dakwah agar bisa

\footnotetext{
${ }^{26}$ Alex Sobur, Dakwah Alternatif . . . hal. 439

${ }^{27}$ Samsul Munir Amin, Rekonstruksi . . . hal. 171-172
} 
menguasai kecanggihan teknologi informasi, agar bisa mengimbangi dengan peradaban yang ada sekarang.

\section{REFERENSI}

Amin, Samsul Munir. 2008. Rekonstruksi Pemikiran Dakwah Islam. Jakarta: Amzah.

Anwar, Chairil. 2000. Islam dan Tantangan Kemanusiaan Abad XXI. Yogyakarta: Pustaka Pelajar.

Baqi, M. Fuad Abdul. Al-Mu'jam Al-Mufahraz li Alfazh Al-Qur'an. Cairo: Dar Al-Kutub Al-'Arabiyyah.

Mahfudz, Syaikh Ali. Hidayat Al-Mursyidin.

Nafis, Abdul Wadud. 2009. Metode Dakwah Teori dan Praktik. Jakarta: Mitra Abadi.

Natsir, M. 1996. Fungsi Dakwah Perjuangan. Yogyakarta: Sipres.

Aziz, Mohammad Abdul. 2018. Netizen Jurnalisme dan Tantangan Dakwah di Media Baru. Islamic Comunication Journal, Vol. 3, No. 2, Juli-Desember.

Purwanto, Yedi, dkk. 2017. Peran Teknologi Informasi dalam Perkembangan Dakwah Mahasiswa. Jurnal Sosioteknologi Vol. 16, No.1, April .

Rubawati, Efa. 2018. Media Baru: Tantangan dan Peluang Dakwah. Jurnal Studi Komunikasi, Vol. 2, Ed. 1, Maret.

Sobur, Alex. 2001. Dakwah Alternatif di Era Global: Suatu Pendekatan Perubahan Sosial. Mimbar, No. 4, Th. XVII, Oktober-Desember.

Tajuddin, Yuliyatun. 2014. Wali Songo dalam Strategi Komunikasi Dakwah. Jurnal Addin, Vol. 8, No.2, Agustus.

Juraid, Razikin. http://m.hidayatullah.com (diakses tanggal 08 Februari 2019) 